\title{
Metaforis dalam Lirik Lagu Populer Bertemakan Percintaan
}

\author{
M. Hermintoyo \\ Fakultas Ilmu Budaya, Universitas Diponegoro \\ hermintpujangga@gmail.com
}

\begin{abstract}
The lyrics of the song are like the poetry of an aesthetic element that builds them as intrinsic elements, such as diction, rhyme, images and rhetorical means. In the hands of creative authors will create an interesting private diction diction and bring up beautiful metaphors. Song lyrics are created based on the author's emotional expression both from personal experience and see around him as the object of his creation. One of the most widely made is the lyrics of the song with the theme of romance, both ranging from approach / introduction, romantic seduction to the sadness left by her lover. This article discusses the metaphorical phrases in the lyrics of popular songs with the study of aesthetics, the elements that build the lyrics and their meaning.
\end{abstract}

Keywords: metaphorical, poetic, lyrics, hermeunetik, expression continuity

\section{Intisari}

Lirik lagu tak ubahnya seperti puisi ada unsur estetis yang membangunnya berupa unsur intrinsiknya, seperti diksi, rima, imaji dan sarana retorika. Di tangan pengarang yang kreatif akan memunculkan diksi private symbol yang menarik dan memunculkan metaformetafor yang indah. Lirik lagu diciptakan berdasar ekspresi emosional pengarangnya baik dari pengalaman pribadi maupun melihat di sekitarnya sebagai objek penciptaannya. Salah satu yang paling banyak dibuat adalah lirik lagu yang bertemakan percintaan, baik mulai dari pendekatan/pengenalan, rayuan romantisnya sampai pada kesedihan ditinggal kekasihnya. Artikel ini membahas kalimat-kalimat metaforis dalam lirik lagu populer dengan kajian estetikanya, yaitu unsur yang membangun lirik dan maknanya.

Kata kunci: metaforis, puitis, lirik, hermeunetik, ketaklangsungan ekspresi

\section{Pendahuluan}

Kalimat-kalimat metaforis dalam puisi/ lirik lagu sengaja dipakai sebagai fungsi imajinatif yang dilakukan pengarang sebagai ungkapan eksprersi puitis. Efek puitis sebenarnya tidak hanya pada diksi puitisnya saja, tetapi ada unsur lain seperti persajakan, bunyi/ rima, imaji dan sarana retorika.

Lirik seperti halnya puisi sebagai karya kreatif dapat dilihat dalam tiga hal yaitu (1) sebagai ekspresi penyair/ sosok pribadi pengarangnya; (2) sebagai dunia dalam kata; (3) sebagai penciptaan kembali atau refleksi kenyataan; (4) sebagai sesuatu yang dikehendaki untuk atau yang mampu mencapai tujuan tertentu dalam diri audiens (Sayuti 2002:23). 
Sebagai sosok pribadi menunjukkan bahwa puisi itu ekspresi personal, artinya puisi itu luapan perasaan atau sebagai produk imajinasi pengarangnya. Dengan demikian, aspek emosional sangat mendominasi, dan dapat dikatakan puisi adalah bahasa perasaan. Sebuah puisi itu membawa perasaan pribadi pengarangnya, semua itu tercermin dalam pilihan kata yang dipakai apakah memakai blank symbol/ simbol kosong( simbol dengan diksi yang pengertiannya sudah umum) maupun private symbol/ simbol khusus (simbol dengan diksi baru dari hasil ciptaan si pengarangnya) (Aminudin, 2000:140-142). Katakata imajis yang dipakai pengarang juga menunjukkan pengalaman dan pengetahuan pribadi pengarangnya dalam menghidupkan simbol-simbol yang dipilihnya.

Sebagai dunia dalam kata, puisi (lirik) merupakan suatu objek yang mencukupi dirinya sendiri yang bersifat otonom. Puisi dibuat dengan pilihan kata maupun susunan yang baik, dan ada koherensi internal. Dengan demikian, fungsi bahasa yang menonjol adalah bersifat puitik, yakni fungsi untuk menggambarkan makna seperti yang terdapat dalam lambang kebahasaan itu sendiri.

Sebagai refleksi realitas menunjukkan puisi (lirik lagu) itu berhubungan dengan kenyatan. Puisi adalah imitasi, refleksi, atau representasi dunia dan kehidupan manusia (Sayuti, 2002:23). Jadi, fungsi bahasa dalam puisi (lirik lagu) dapat bersifat referensial, yaitu fungsi yang menggambarkan objek, peristiwa, benda, pandangan, atau sikap yang akan di sampaikan lewat imajinya..

Alat untuk menyampaikan perasaan dan pikiran pengarang adalah bahasa. Baik tidaknya bergantung pada kecakapan pengarang dalam menggunakan kata-kata. Pengarang dalam mencurahkan perasaan dan isi pikiran yang setepat-tepatnya haruslah memilih kata yang pas dan dapat menimbulkan imajinasi estetik yang hasilnya disebut diksi puitis (Pradopo 1987:54).

Untuk mendapatkan kepuitisan, pengarang dapat menggunakan bahasa kiasan (figurative language). Dengan bahasa kiasan ini lirik menjadi semakin hidup yang dapat memberikan ciri puitis. Kiasan ini berupa kalimat metaforis. Wahab (1995:42) menyebutkan metafora adalah ungkapan kebahasaan yang maksudnya tidak dapat dijangkau secara langsung dari lambang yang dipakai karena makna yang dimaksud terdapat pada prediksi ungkapan kebahasaan itu. Dengan kata lain, metafora adalah pemahaman dan pengalaman akan sejenis hal yang dimaksud untuk perihal lain. 
Meneliti puisi pada hakikatnya adalah upaya untuk menyingkap makna puisi tersebut. Seperti dikatakan Pradopo (1987:120) bahwa menganalisis puisi adalah memberi makna kepada teks puisi tersebut. Untuk bisa memberi makna sebuah puisi, perlu dianalisis unsurunsur strata norma puisi tersebut. Untuk bisa melakukannya, diperlukan pengetahuan tentang sistem kode bahasa dan kode budaya yang sesuai dengan puisi tersebut (Teeuw 1983:15). Pengetahuan tentang sistem kode bahasa dan kode budaya diperlukan untuk menangkap makna puisi yang diungkapkan penyair/ pengarang secara khas dalam bentuk puisi. Pengetahuan kosa kata dan tata bahasanya sangat diperlukan agar teks itu dapat dipahami, tetapi pengetahuan kode bahasa belum cukup karena masih memerlukan pengetahuan kode budaya. Sebuah kata akan menjadi simbol yang bermakna jauh dari makna harfiahnya akibat kode budayanya. Sebagai contoh terjemahan puisi bahasa Jawa Kuno (9) // di sana di puncak gunung aku memuja-muja sekuat tenaga / mencari keakraban Tuhan / menatapi turunnya batara Wisynu yang dibayangkan duduk di atas bunga teratai/. Dalam agama Hindu batara Wisynu adalah Dewa yang memelihara dan menguasai alam semesta; bunga teratai lambang agama Hindu. Larik tersebut menggambarkan seseorang yang sedang berdoa agar bisa bertemu dengan Tuhannya. Kode sastra terlihat dalam aturan alinea yang berupa bait, sajak, bunyi, citraan, bahasa figuratif dsb.(Teeuw 1983: 12-21).

Pengetahuan tentang kode bahasa belumlah cukup untuk menyingkap makna sebuah puisi. Makna puisi bukan semata-mata arti bahasanya, melainkan arti bahasa dan suasana, perasaan, intensitas arti, arti tambahan, daya tarik dan tanda-tanda kebahasaan (Pradopo 1987:122). Lebih lanjut Luxemburg (1984:177-181) menambahkan bahwa untuk menganalisis sebuah puisi perlu dikenali situasi bahasa yang terdiri atas pembicara dan yang diajak bicara.

Metafora berwujud kata-kata yang berupa simbol dengan berbagai jenisnya, dan pemaknaan simbol-simbol itu membutuhkan makna konteks terutama dalam mengungkap implikaturnya sesuai dengan konvensi bahasa, sastra, maupun budaya.

Konvensi bahasa meliputi diksi, baik yang berupa lambang maupun simbol, struktur sintaktisnya; Konvensi sastra dalam hubungannya dengan pemaknaan puisi adalah ketaklangsungan ekspresi, yaitu menyatakan pikiran atau gagasan secara tidak langsung/ dengan cara lain. Ketidaklangsungan ekspresi itu menurut Riffaterre (1978:2) disebabkan 
oleh tiga hal, yaitu penggantian arti (displacing of meaning), penyimpangan arti (distoring of meaning), dan penciptaan arti (creating of meaning).

\section{Metode Penelitian}

Metode penelitian yang digunakan adalah metode pustaka dan simak. Data diambil dari lagu populer dengan cara acak atau random sampling. Data yang diambil dianggap sudah representatif mewakili data yang diharapkan, yaitu data lagu yang liriknya bertema percintaan. Analisis data dilakukan dengan pembacaan hermeunetik yaitu dengan mempfaraprasakan kalimat metaforis yang ada dalam lirik lagu.Teori yang digunakan dengan metode ketaklangsungan ekspresi Rifarterre. Ketidaklangsungan ekspresi disebabkan tiga hal yaitu (1) adanya penggantian arti, (2) penyimpangan arti, (3) penciptaan arti. Penggantian arti tercermin dalam metafora baik yang berupa pembandingan, pemanusiaan, maupun penggantian. Penyimpangan arti tercermin dalam makna ambiguitas, kontradiksi, dan nonsense.

\section{Hasil dan Pembahasan}

Lirik yang bertemakan percintaan atau serenada jika isinya menggambarkan percintaan baik yang berupa curahan perasaan, harapan, dambaan, kekaguman, kekecewaan, patah hati, kehilangan pada seseorang. Kalimat metaforisnya mendukung sarana retorika dalam memberikan suasana konteksnya.

\section{(1) Mata indah bola pingpong}

Apa kau masih kosong

(Iwan Fals: Mata Indah Bola Pingpong)

Metafora (1) dengan private symbolbola pingpong; bercitraan penglihatan; bersajak aa dengan bunyi ong yang menandakan hampa; berimplikatur kekaguman seseorang lelaki terhadap wanita yang bermata indah, lincah, dinamis, tetapi berkemungkinan akan pudar jika tidak di tangan yang tepat.

Praanggapannya mata itu indah seperti bola pingpong. Bola pingpong itu bundar berwarna warni ada yang putih, kuning, hijau, biru ;dapat bergerak lincah, dinamis kadang pelan, kadang keras, kadang meliuk sulit ditebak arahnya dan dibutuhkan pemain yang handal dalam memainkannya; bola itu pun akan rusak jika dimainkan secara sembrono dan terpuruk di tong sampah. Inti dari metafora di atas adalah ketertarikan seseorang dan ingin berkenalan bahkan menjadikannya pacar. 
Berbeda dengan Iwan Fals, metafora lirik lagu Populer karya Jamrud meskipun sama-sama menggambarkan kekaguman implikaturnya menggambarkan seorang lelaki yang mengagumi kekasihnya dengan melihat matanya yang penuh keindahan dengan metafora ada pelangi di bola matamu.

(2) ada pelangi di bola matamu

dan memaksa diri berkata aku sayang padamu

(Jamrud: Pelangi di Matamu)

Lambang dan private symbolpelangi dipilih dengan citraan penglihatan menggambarkan ada keindahan yang romantis di mata kekasihnya.

Pranggapannya pelangi adalah peristiwa alam yang indah berwarna warni yang dalam mitos di Jawa sebagai tempat jalan bidadari cantik dari kahyangan yang sedang mandi di telaga. Metafora itu sengaja dipakai untuk menggambarkan kecantikan alami yang dimiliki seorang wanita seperti gambaran bidadari. Begitu juga dengan lirik lagu Katon “ Bagai Bidadari” berikut:

(3) kau bagaikan bidadari

ranum semerbak anggurmu

terhirup dan memabukkan hati

inginkupetik pelangi

jadi tiara indah rambutmu

kejora di sinar matamu

Metafora dengan simbol bidadari, bercitraan penglihatan, penciuman dan rasa //ranum semerbak anggurmu memabukkan hati// berkategori flora, pada metafor kupetik pelangi, bercitraan penglihatan demikian juga yang lain jadi tiaraindah, kejora di sinar matamu

Praanggapannya bidadari itu cantik, kecantikan itu memabukkan bagai anggur. Kecantikan itu indah dapat dipadukan dengan pelangi yang berwarna warni, seperti kecantikan ratu dengan mahkotanya (tiara indah). Keindahan juga adadi sinar matamu seperti bintang kejora. Implikatur metafora (3) menggambarkan seseorang yang sedang jatuh cinta pada seorang gadis yang cantik sempurna baik tubuh maupun matanya.

(4) Akulah Arjuna yang sedang mencari cinta

(Dewa: Arjuna Mencari Cinta)

Lambang dan blank symbolArjuna bercitraan penglihatansebagai mitos orang Jawa bahwa tokoh pewayangan Arjuna adalah tokoh play boy, ngganteng, kesatria sakti yang tidak pernah gagal bercinta, namun dalam metafora lirik lagu tersebut malah sebaliknya sebagai 
seseorang play boy yang sedang menawarkan cintanya, memohon pada seseorang agar mencintainya.

Praanggapannya Arjuna tokoh yang ngganteng; perayu ulung; sakti, tidak pernah gagal. Implikatur metafora (4) dengan memakai simbol Arjuna diharapkan dapat memberikan sugesti bahwa perayu semacam Arjuna tetap akan berhasil dalam bercinta..

Jamrud dalam lirik lagunya "Surti Tejo" juga menggunakan simbol nama Arjuna bercitraan penglihatan //malam selimuti desa//, bercitraan perabaan //Jemari Tejo mulai piknik/mirip demo memasak Tejo mulai berakting//. Praanggapan metafora, Arjuna adalah seorang tokoh yang tampan, pujaan hati. Kerinduan mereka mengajak kencan di sawah pada malam hari yang harus menyerahkan kesuciannya dengan perilaku seks model sekarang agar tidak hamil dengan alat kontrasepsi. Implikatur metafora (5) menggambarkan bahwa ketampanan seperti Arjuna dapat membuat seseorang lupa diri dalam melepas kerinduannya sehingga terenggut kesuciannya.

(5) Surti sumringah Arjunanya pulang

Tiga tahun berpisah nyari dana di kota

Mereka melepas rindu di pematang sawah

Hingga malam selimuti desa

Jemari Tejo mulai piknik dari wajah sampai lutut Surti

Tanpa sadar sarung mereka pun jadi alas

Mirip demo memasak Tejo mulai berakting di depan Surti

Masang alat kontrasepsi

(Jamrud)

Cinta membawa suasana yang melankolis, kenangan-kenangan indah masa lalu tidak mudah terhapus dan berusaha mencari, dan menikmati suasana yang sudah berlalu, dan cinta tidak bisa diberikan pada yang lain, seperti yang terlihat dalam lirik berikut ini :

(6) bulan merah jambu luluh di kotamu

kuayun sendiri langkah-langkah sepi

menikmati angin menabuh daun-daun

mencari kembaranmu di waktu lalu

sisi ruang batinku hampa rindukan pagi

tercipta nelangsa merenggut sukma

terwujud keinginan yang tak pernah terwujud

aku tak bisa pindah

pindah ke lain hati

begitu lelah sudah ku harus menepi

biduk t'lah ditambatkan berlabuh di hatimu

(Katon/KLA Projek: Tak Bisa Ke Lain Hati) 
Lambang dan simbol yang digunakan adalah kata bulan,angin, daun-daun, pagi, pantai, merenggut dan menabuhdiambil dari alam dan flora. Citraan penglihatan terlihat pada gambaran bulan, biduk; citraan pendengaran terlihat pada menabuh daun-daun.

Praanggapannya bulan mestinya berwarna putih tetapi merah jambu. Merah jambu adalah simbol warna romantis. Kesepiannya (kuayun sendiri langkah-langkah sepi). Hanya kerinduan yang terasa ( menikmati angin menabuh daun-daun). Simbol angin yang selalu bergerak adalah simbol kerinduan sedangkan menabuh daun-daun adalah simbol kehidupan. Batinnya tidak bisa memungkiri ada kehilangan cinta (rindukan pagi) sehingga sampai tak berdaya (tercipta nelangsa merenggut sukma), tetap kehilangan harapan tetapi cintanya tetap ada. Keputusasaan dirasakan pula (begitu lelah sudah ku harus menepi). Cintanya tetap untuk kekasihnya (biduk t'lah ditambatkan berlabuh di pantaimu).

(7) bunga melati pujaannya dari kuncup dia sirami harapan yang suci telah diucapkannya kelak akan memetik bunganya ia berkelana demi masa depan berdua kuncup melati mulai semerbak, semerbak melati banyak kumbang datang menjelang mengisap sari bunga melati sebulan dia berkelana betapa hancur hatinya melati pujaan yang didambakannya kini telah layu penuh noda (Bimbo: Bunga Melati)

Implikatur metafora (7) menggambarkan seseorang yang kecewa, kehilangan harapan karena kekasihnya yang masih perawan, dia kenal sejak belum dewasa ternyata setelah dewasa dia menemukan calon istrinya itu tidak perawan lagi karena banyak bergaul dengan banyak lelaki petualang cinta.

Lambang dan blank symbol yang dipakai adalah bunga melati kategori flora merupakan simbol orang Jawa. Melati adalah bunga simbol kesucian.Pada upacara pernikahan bunga melati selalu dipakai pengantin wanita di sanggulnya, kamar pengantin juga ditaburi bunga melati. Tari Jawa seperti Serimpi, tari golek kencono juga memakai simbol bunga melati yang melambangkan bahwa penarinya masih perawan. Dalam adegan naik kendi pada tarian golek kencono pecah dan tidaknya kendi membuktikan keperawanannya.. Kecepatan layu bunga menentukan sekali kesucian seorang pengantin, maupun penari. Simbol kumbang yang berkategori fauna merupakan lambang kejantanan. 
Kumbang adalah serangga yang selalu menghisap sari bunga dari bunga satu ke bunga lainnya. Simbol kumbang mewakili lelaki play boy yang tidak bertanggung jawab.

Jika metafora lirik lagu di atas hanya sepihak yang menderita, lirik metafora berikut ini kedua pasangan mengalami kesulitan dalam bercinta.

(8) surya tenggelam di telan kabut kelam

surya yang muram di hati remuk redam

jalan berliku jalan kehidupan

dua remaja kehilangan

penawar rindu kasih pujaan

menempuh cobaan

(Chrisye: Kala Sang Surya Tenggelam)

Lambang dan simbol surya berkategori energi menunjukkan ada kehidupan, semangat, tetapi simbol tenggelam yang menggambarkan energi yang hilang; kabut berkategori lembam menutup atau menghalangi; kelam dan redam ada suasana yang tidak nyaman. Jadi, simbol-simbol dalam metafora (8) menggambarkan kehilangan daya, terhalang, dan tidak nyaman. Bunyi persajakanlam dan dam menambah suasana semakin tidak nyaman dan hancur. Implikatur metafornya menggambarkan dua pasang remaja yang tidak menemukan kebahagiaan dalam bercinta.

Jika metafora lirik lagu di atas menggambarkan percintaan tentang kekaguman, kesulitan, kekecewaan ada juga yang menggambarkan keanehan dalam tingkah lakunya akibat jatuh cinta. Misalnya metafora lirik lagu berikut ini:

(9) sejak engkau bertemu lelaki bermata lembut ada yang tersentak dari dalam dadamu kau menyendiri duduk dalam gelap bersenandung nyanyian kasmaran dan tersenyum entah untuk siapa nampaknya kau tengah mabuk kepayang kau penuhi dengan angan-angan kau ukir malam dengan bayang-bayang

(Ebid G Ade: Kasmaran)

Bait lirik lagu tersebut menggunakan simbol disemua baitnya menggambarkan seorang gadis yang sedang jatuh cinta pada seorang lelaki yang bermata lembut; jadi penyendiri; bertingkah aneh suka tersenyum sendiri; selalu berangan-angan; setiap malam membayangkan sang pujaan hatinya. Simbol ukir malam dengan bayang-bayang merupakan privae symbol orang jatuh cinta dengan kesunyian, kesendirian, dan penuh mimpi. 
Pada metafor berikut berimplikatur kesedihan akibat ditinggal kekasihnya

(10) batu hitam di atas tanah merah

di sini kutumpahkan rindu

kugenggam lalu kutaburkan kembang

berlutut dan berdoa sorgalah di tanganmu

Tuhan di sisimu

Kematian hanyalah tidur panjang

Maka mimpi indahlah engkau, Camelia...oh

Pagi, engkau berangkat hati mulai membatu

Malam kupetik gitar dan terdengar senandung ombak di lautan

Menambah rindu dan gelisah

Adakah angin gunung

Adakah angin padang

Mendengar keluhanku

Dan membebaskan nasibku

Dari belenggu sepi.

(Ebid G Adfe: Camelia IV)

Simbol kematian diwakili batu hitam demikian juga simbol nisan, tanah merah gambaran baru saja meninggal, taburan kembang berkategori flora merupakan simbol kejawen atau agama Hindu bahkan sudah tradisi tidak hanya yang beragama Hindu pun setiap ke makam diusahakan dengan menabur kembang kemudian berdoa. Bagi Ebid kematian dapat diartikan sebagai tidur yang panjang dan berharap di surga (mimpi indahlah engkau, Camelia).

Pada bait berikutnya kesedihan akibat kematian itu akhirnya tidak bersemangat (membatu), selanjutnya melarikan diri dengan bermain musik dan ke luar ungkapan hati yang bergemuruh seperti ombak menambah kerinduan, gelisah dan berharap ada yang bisa mengabarkan pada kekasihnya (angin lambang pembawa berita) tentang kesepiannya (belenggu sepi).

\section{Simpulan}

Berdasarkan uraian di atas dapat disimpulkan metafor dalam lirik lagu populer menggunakan unsur-unsur puitis seperti adanya diksi yang blank symbol, private symbol serta menggunakan imaji yang tepat sesuai objek yang dibicarakan. Lirik percintaan adalah lirik yang menarik dari permasalahan perkenalan, pengungkapan perasaan, rayuan, dan kesedihan. Di tangan pengarang yang kreatif akan tercipta diksa yang menarik dan 
indah. Metafor-metafor yang diciptakan menunjukkan estetika dari ciri masing-masing penciptanya/ pengarangnya.

\section{Daftar Pustaka}

Aminudin.2000. Pengantar Apresiasi Karya Sastra. Bandung: Sinar Baru.

Luxemburg, Jan Van, dkk. 1984. Pengantar Ilmu Sastra. (Terj.) Dick Hartoko. Jakarta: Gramedia.

Pradopo, Rahmat Djoko. 1987. Pengkajian Puisi. Yogyakarta: Gajah Mada University Press.

Riffaterre, Michael. 1978. Semiotic of Poetry. Blomington and London: Indiana University Press.

Sayuti, Suminta A. 2002. Berkenalan dengan Puisi. Yogyakarta: GamaMedia.

Teeuw, A. 1983. Membaca dan Menilai Sastra. Jakarta: Gramedia.

Wahab, Abdul. 1995. Isu Linguistik. Surabaya: Airlangga University Press.

Waluyo, Herman J. 1987. Teori dan Apresiasi Puisi. Jakarta: Erlangga. 